\title{
EXAMINING DIGITAL TECHNOLOGY FOR (HIGHER) EDUCATION THROUGH ACTION RESEARCH AND CRITICAL DISCOURSE ANALYSIS
}

\section{Z. Waghid}

Faculty of Education and Social Sciences

Cape Peninsula University of Technology

Mowbray, South Africa

e-mail:waghidz@cput.ac.za

\section{F. Waghid}

Centre for Learning Technologies

Stellenbosch University

Stellenbosch, South Africa

e-mail: Faiq@sun.ac.za

\section{ABSTRACT}

The public understanding of scientific, economic, political and ethical issues is becoming increasingly important as students are confronted with socio-economic issues impacting their everyday lives. Grappling with these issues requires critical, deliberative and autonomous students. According to Wankle $(2011,7)$, the use of digital technology in education may serve as a catalyst for cultivating excitement, interaction and sharing in students. In this article, the authors, using two distinct research methodologies, argue that using Facebook as a digital technological methodology in (higher) education could provide a means of mediating and communicating in today's modern society, so that (higher) educationists can engage with students both deliberatively and critically so as to enhance students' understanding of current economic, political and cultural issues autonomously. The authors posit that the application of digital technology can be implemented successfully if students and (higher) educationists possess the capabilities to do so.

Key words: action research, critical discourse analysis, digital technology application, autonomous learning, critical thinking, deliberation, teaching, learning, professional development, higher education

\section{INTRODUCTION}

South African higher education institutions are faced with major obstacles in the provision of effective teaching and learning practices, and this is due to students not being adequately prepared for individual courses and their medium of instruction, with socioeconomic factors 
hindering the needs of the majority of historically disadvantaged students in the country (Badat 2010, 8). These obstacles place a tremendous strain on traditional methodologies with regard to efficacy and efficiency in curriculum policy implementation (Badat 2010, 8).

The public understanding of scientific, economic, political and ethical issues is becoming increasingly important as students are confronted with issues affecting their everyday lives. Grappling with these issues requires critical students. According to Jenkins (1999, 703), there are inextricable links between (higher) education, citizenship and this public understanding. He argues further that (higher) education should play a prominent role in the development of critical thinking in students. However, traditional teaching methodologies, commonly referred to as 'chalk and talk' methodologies, may place constraints on the development of deliberative spheres for the advancement of critical thinking. Within the current digital age, (higher) educationists are being challenged to use digital technologies in the education setting to effectively facilitate deliberative events in which students can critically engage with one another (Wankle 2011, 3).

The application of digital technology in a (higher) education context may afford teaching and learning spaces to become more social, allowing students to make their voices heard - voices that otherwise would be muted in traditional pedagogical activities (Wankle 2011, 7). The use of digital technology in (higher) education could potentially stimulate technical literacy, social interaction and critical reflection (Wankle 2011, 6). According to Wankle $(2011,7)$, the use of this technology may serve as a catalyst for cultivating excitement, interaction and sharing in students. Studies done on deliberation and the Internet indicate that users of the latter, that is, the Internet, are more tolerant of non-conforming views than non-users (Robinson, Neustadtl and Kestnbaum 2002, 285). This indicates that digital technology could enhance inclusivity and equality if all have access to these information and communication technologies.

Research has shown that the application of digital technology has enhanced teaching and learning. In several studies conducted by Underwood $(2009,8)$ on the impact of digital technology application in education, she posits that there is a clear resonance between the application of digital technology in class and students' academic performance and behaviour. We contend that there needs to be an improvement in the skills of (higher) educationists in the use of digital technology, and this is reiterated by Underwood (2009, 8), who argues that a skilled teaching force is considered a key ingredient in improving both the behaviour and academic performance of students. It also is a key ingredient in the context of this study, which intends to show how a digital teaching methodology such as the social media site 
Facebook can be used as a learning platform to enhance students' capacities to think critically, act autonomously and engage deliberatively. Further research on the application of digital technology in (higher) education points out that the collaborative application of digital technology, that is where students work in pairs, has been shown to be more effective than individual work, and by supporting students with special needs, including students from historically disadvantaged groups, they are able to keep up with their more advanced and affluent peers (Higgins, Xiao and Katsipataki 2012, 4).

Despite a growing concern about the cost effectiveness and relative benefit of using digital technology in (higher) educational practices from sceptics such as Wainer et al. (2008, 24), we agree with enthusiasts such as Underwood (2009) and Higgins et al. (2012) on the efficacy and effectiveness of using digital technology in a (higher) education context, and are of the view that students' critical thinking and deliberative engagements could only be enhanced through the efficient and effective implementation of digital technology in the curriculum.

For the purposes of this article we argue that the effective application of digital technology, facilitated through the use of two different research methodologies, that is critical discourse analysis (CDA) and action research (AR), can be used to cultivate autonomous and critical learning and deliberative enquiry. As this article investigates how the application of digital technology in a school setting can be used to enhance its application in (higher) education, it has been guided by the research question - is there sufficient evidence to show that teaching with the aid of digital technology in two educational settings enhances autonomous learning, critical learning and deliberative enquiry?

Furthermore, we are of the view that, through the use of the social media site Facebook as a learning platform in a (higher) educational setting, one is provided a means of mediating and communicating in today's modern society, and this could be seen as a means by which (higher) educationists engage with students both deliberatively and critically so as to enhance students' understanding of current economic, political and cultural issues. This article can be considered most apposite, as it investigates how the application of digital technology in two different grades, namely a Grade 11 Economics class and a Grade 10 Life Sciences class at a local historically disadvantaged high school in Cape Town, is used to enhance the teaching and learning required for a (higher) education context. 


\section{THEORETICAL UNDERPINNINGS OF ACTION RESEARCH AND CRITICAL DISCOURSE ANALYSIS}

\section{Action research}

A qualitative research design offers a researcher the opportunity to explore new territory (Denscombe 1999, 92). Action research was one of the research designs selected for this qualitative research, as it affords a researcher the prospect of improving both personal and social situations (McNiff and Whitehead 2006, 13). Additionally, action research constitutes individuals looking at themselves in relation to others. It therefore can be seen as an inclusive methodology helping to foster respectful relationships amongst individuals in a given context (McNiff and Whitehead 2006, 14). Action research has been used with much success by social scientists in many small-scale research projects and is described as being a very 'hands on approach' (Denscombe 1999, 123). In action research, the researcher is acquiring the identity of a 'practitioner' (Denscombe 1999, 123). As a practitioner conducting action research, an individual is required to clarify visions and targets, articulate and implement theory, collect (or construct) data, reflect on data and plan informed action to address the identified visions or targets. In this instance, the targets identified were to address, through the appropriate application of digital technology, deficiencies such as student autonomy, deliberation and critical thinking among students in (higher) education contexts.

Elliott $(1991,6)$ considers action research as 'the study of a social situation with a view to improving the quality of the action within it'. The adoption of action research in this study helps (higher) educationists to deal with the challenges and problems of practice in a reflective manner (Altrichter et al. 1998, 6). Action research necessitates reflection on practices so as to fortify and cultivate progressive features, such as the introduction of digital technology (Altrichter et al. 1998, 6). AR encourages (higher) educationists to experiment with new ideas and strategies, rather than being afraid of curriculum innovations such as using digital technology to augment teaching and learning (Altrichter et al. 1998, 6).

Action research studies are characterised by the implementation of a cyclical method, as can be seen in Figure 1. 


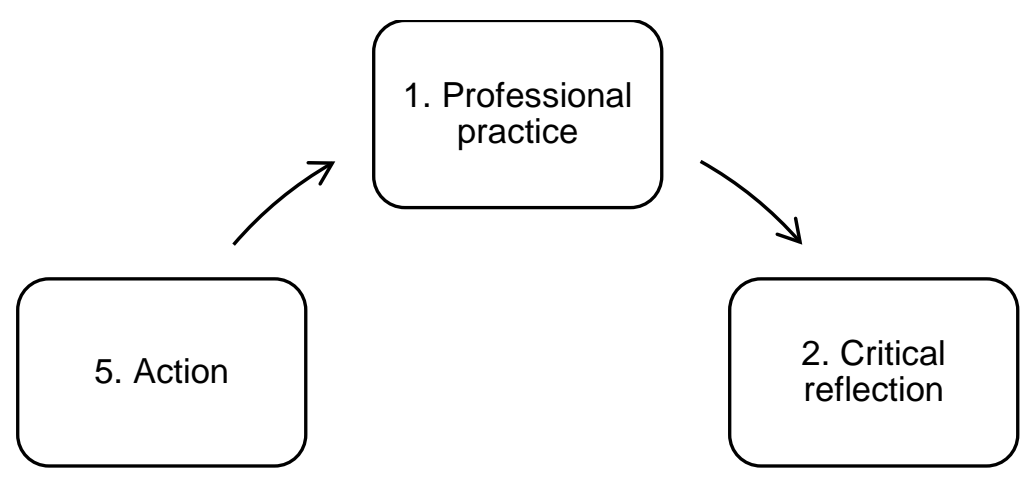

Investigate change

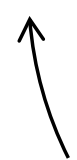

Identify problem, or evaluate changes

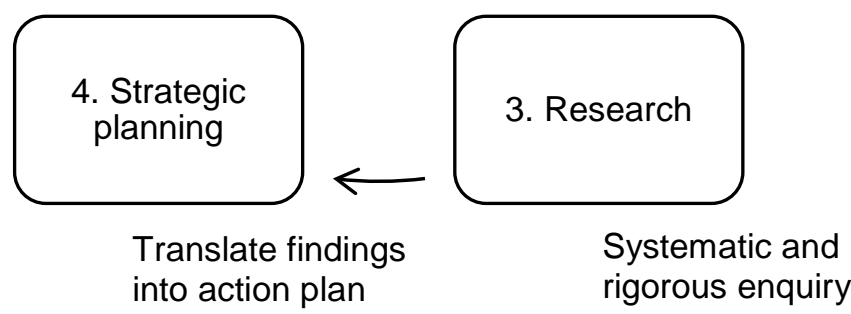

Figure 1: A cyclical method of action research as suggested by Denscombe $(1999,126)$.

\section{Critical discourse analysis (CDA)}

Critical discourse analysis (CDA) is a particular category of discourse analysis (DA) that focuses on an analysis of the linguistic features of a text in relation to the social discursive practices that have given rise to the production of the text (Fairclough 2003, 156). CDA aims to address the often 'negative' power relations that dominate people's social practices (Janks 1998, 198) with the aim of producing more equitable relations amongst them (Jorgensen and Phillips 2002:64). CDA therefore aims to undermine subordinating power relations amongst people; for instance, in the context of this study, the often asymmetrical power relations that exist between a (higher) educationist and students in a class. The approach to CDA that we use in this article draws on the work of Norman Fairclough (2003). His approach to CDA focuses first on an analysis of broad semiotic elements of social life, such as written language or text, visual semiosis and body language; and second on representations of social life that highlight problems of inequity, poverty, disadvantage and exclusion (Fairclough, Jessop and Sayer 2004).

Fairclough's account of CDA involves the following interrelated strategies: First, through linguistic analysis and semiotic analysis one can focus on describing a text by making clear the argument being made or story being told, who the speaker is, to whom is 
being spoken, and the style of speaking being done (Fairclough 2003, 81). The purpose is to ascertain the patterns of representation in a text so that one can clarify the discursive practices in a social setting (Janks 2005, 331). Second, discursive analysis or interpretation of the text involves looking at the discourses at play in the text from both the perspective of the author who produced the text and the receiving audience of the text. Third, Fairclough's approach looks at the larger social context in which the text was produced, such as the socio-political and historical circumstances that framed the text. Hence, CDA involves a description, interpretation and explanation as one endeavours to 'look for patterns across texts related so as to form an order of discourse, or for discontinuities and hybridity which can signal disorder and social change' (Janks 1998, 197). Hence, in doing critical discourse analysis (CDA), one textually and contextually examines what can, should or will happen in a particular situation; and one produces the necessary arguments that can either reinforce one's claims, or undermine one's position or points of view.

The focus of this article is on evaluating the application of digital technology and analysing aspects of texts (engagements on Facebook among students) with the aim of cultivating autonomous learning, critical thinking and deliberative transformative practices. Hence, we are attracted to Fairclough's account of CDA as a second research design. In the next section we provide theoretical underpinnings of digital technology application in (higher) education in relation to critical learning, autonomous learning and deliberative enquiry.

\section{AUTONOMOUS LEARNING, CRITICAL THINKING AND DELIBERATIVE ENQUIRY AS INSTANCES OF THE APPLICATION OF DIGITAL TECHNOLOGY}

The application of digital technology in (higher) education can be considered of great benefit to (higher) educational institutions (Gane 2005, 471), with common agreements suggesting that such application in different domains plays something of a facilitative role in the overall improvement of and transformation in contemporary society (Selwyn 2011, 2). Gane (2005, 471) posits that Internet-related technology has integrated itself into our everyday lives, revolutionising the way we work, access and exchange information, shop, and interact with people to maintain social ties.

The integration of digital technology into society has not merely added to our social arrangements, but rather altered them in spheres such as social life, production, consumption, communication and how we learn (Gane 2005, 471). It therefore could be claimed that (higher) education to some extent resonates with digital technology, as both involve the 
production and dissemination of knowledge through interaction with others. This affiliation between (higher) education and digital technology suggests that (higher) education is a key area for the improvement and change of teaching and learning (Selwyn 2011, 22).

Van der Merwe $(2004,91)$ argues that digital technologies in (higher) education do not necessarily promote deep learning; however, when used in accordance with principles of deep learning, pedagogical practices can be nurtured. Such an implementation of digital technology in (higher) education can enhance knowledge transmission and the quality of (higher) educationists (Gimbert and Cristol 2004, 207). Jeremy (2000) suggests, by applying digital technology in (higher) education to promote socialisation and language development, there arises the opportunity to promote deliberation and, as a consequence, enhance critical thinking. Through this active engagement, characterised by the sharing of experiences and interpretations, the process of learning may be improved (Jeremy 2000, 77).

The promotion of deliberative opportunities and critical thinking, and the enhancement of autonomous learning are invariably linked to digital technologies in (higher) education as creating 'virtual places', in which communication, community building and the coconstruction of 'knowledge' can occur (Smeyers and Depaepe 2007, 7). This is echoed by Burbules (2007, 44), who describes these 'virtual places' as spheres where people spend time, interact and work in collaboration. MacKnight $(2000,39)$ also mentions that these 'online communication hubs' place great emphasis on students' comprehension and knowledge of an argument and on how to interact meaningfully with one another in relation to their ideas. The latter would relate to asking the right questions, listening to one another, sharing work, respecting one another's ideas, and constructing understandings in new ways (MacKnight 2000, 39). This opportunity to foster students' critical thinking skills through the establishment of opportunities for students to construct knowledge, rather than to passively digest information, can only be seen as beneficial to the teaching and learning process (Hopson, Simms and Knezek 1991, 110).

Gimbert and Cristol $(2004,208)$ propose that, by using the appropriate digital technology in (higher) education, students are encouraged to use their imagination and to explore at their own pace, based on the nature of the digital technology used. Eisenhart, Finkel and Marion (1996, 261) suggest that such an implementation of digital technology in (higher) education would drive a shift in pedagogies, resulting in a drive for students to become autonomous rather than conformist. The opportunity will exist for students to transfer what is learnt in class and apply it in their everyday communal experiences (Eisenhart et al. 1996, 262). 
Wolff-Michael and Lee (2003, 285) argue that students who participate in activities in which knowledge relating to their communities is produced will develop from adolescents into autonomous individuals who will be able to participate in community activities. (Higher) educationists should be aware that students are not categorised as a homogenous group (Wolff-Michael and Lee 2003, 285), but rather as a heterogeneous group with different intellectual, motivational and emotional needs. Adopting an approach that recognises students' heterogeneity can cultivate the development of student autonomy. Autonomous individuals who contribute to other forms of knowing and relating to the world can contribute to resolving issues in decision-making processes (Wolff-Michael and Lee 2003, 285).

\section{METHODS}

The data compiled was part of two doctoral studies at a historically disadvantaged school in Cape Town. The objective of both research studies was to analyse students' comments using online asynchronous focus group interviews through two distinct Facebook groups. For the purposes of this article we took two samples of screenshots from the studies. The first research study, conducted in 2013, focused on the democratisation of senior phase school science through the application of digital technology, which used three iterations of AR cycles. Twenty-six students participated in three discussions using Facebook as a sphere to facilitate deliberation. Each discussion focused on the discussion of a contentious topic. The second research study, conducted in 2014, focused on an education for social justice through sustainable development, economic development and equity. The purpose of the second study's Facebook group was to afford students the opportunity to engage and deliberate with one another on two films viewed in class in relation to issues of social (in)justice in society. The second Facebook group included 25 students. The students in both research studies had access to the Internet at school via the computer laboratory, which was part of a Khanya Project established in 2002 to assist historically disadvantaged schools with well-equipped computers to enhance teaching and learning. In both studies the students therefore were able to establish individual groups with their peers in order to respond to pedagogical questions posed to the Facebook group.

\section{RESEARCH STUDY 1: GRADE 10 LIFE SCIENCES CLASS}

In each AR cycle there was a discussion on a contentious topic in the Life Sciences curriculum, with Facebook serving as a tool to facilitate student engagement. The contentious topics were cloning, global warming and evolution. Through each iteration of the AR cycle, 
the use of Facebook as a digital technology application was 'fine-tuned' towards ensuring that it was used in the most effective way possible.

With reference to Figure 1, our implementation of AR began with identifying how one of us could improve our own pedagogical activities in a (higher) education context. Through critical reflection, we realised that, except for a few instances, students appeared to be passive participants and, as (higher) educationists, we would often provide the sole input in a lesson. Such a context may be considered as inappropriate for the promotion of learning characterised by skills such as deliberation, critical thinking and learner autonomy. Through a literature review, a number of improvements that could be brought to teaching and learning through the application of digital technology were identified. These improvements were directly related to these skills and included that said application would be able to promote social interaction and the accommodation of heterogeneity, allowing students to express individual strengths that otherwise would have been stifled by traditional teaching strategies (Wankle 2011, 7). Other improvements included the promotion of technical literacy and critical reflection (Wankle 2011, 6). The literature review provided further justification for the use of digital technology.

Facebook was subsequently identified as a form of digital technology that could be used to address the aforementioned shortcomings in the pedagogy used. As AR involves systematic and rigorous enquiry, in the addition of Facebook, as an application of digital technology, into the pedagogy it was necessary to be continuously cognisant of how it could be used to foster deliberation and critical engagement. To ensure this, recorded and analysed field notes in the form of Facebook screenshots were used to actively document shortcomings as they arose. This practice seems to be in agreement with Hardiker's $(1989,16)$ notion that research is a continual interaction between reading, thinking, perusing materials and data, and analyses. Future actions were planned based on the documented field notes and Facebook screenshots. Through these reflections on the Facebook discussions, as a virtual sphere, we could gauge the effectiveness of the implementation of digital technology in (higher) education. These reflections were used to continually 'fine-tune' the implementation of digital technology in subsequent AR cycles.

Investigating the changes to the (higher) educational practices through these field notes in the form of Facebook screenshots, we could procedurally 'store' (record) screenshots authentically for analyses and validation. Through this procedure we could systematically derive new meanings through the analysis of the discussions. A more credible and authentic form of data collection emerged through the use of Facebook. And, as a credible form of 
validation, we could constantly refer to the Facebook discussions and even respond to comments of the students in an effort to acquire their legitimate responses. That is, validation took a different form through constant reference to the Facebook screenshots. It therefore is recommended that the literature on action research be revisited and that new forms of technologically assisted data construction be implemented.

\section{Analysis of Facebook screenshots using action research (AR)}

In the first iteration of the action research cycle, a number of technical glitches were encountered by the students. These related to the students not being able to see the progressing discussions on their mobile devices (many of the students used their mobile devices), creating a situation in which deliberation, critical thinking and learner autonomy, with all students being actively involved, was not possible. The frequency of comments on the discussion on cloning in the Facebook group was minimal.

Through the adoption of an AR approach, the use of Facebook as a digital technology application could be 'fine-tuned' towards addressing the needs of the context in question. Before commencing the second AR cycle, on global warming, attention was paid to addressing the technical issues hampering the discussions on Facebook. Once these issues were resolved, a number of provocative questions were posted. It was hoped that these questions would spark discussions. What was subsequently noted was that Facebook indeed served as a means to facilitate deliberation. However, there were only sporadic instances of students demonstrating critical thinking and learner autonomy. In these sporadic instances, the students were independent of our pedagogical authority and made use of the Internet to search for information to substantiate their comments in the Facebook discussions.

In the third action research cycle we refrained from posting questions to spark off discussion. We felt that the questions posted restricted the students in demonstrating their learner autonomy and critical thinking. With Facebook already serving its role as a deliberative sphere, emphasis was placed on how Facebook could foster critical thinking and learner autonomy. With the contentious topic of evolution, the students were given free range to explore the topic together. What followed was that some students, having gained selfconfidence to express their opinions, came up with unexpected ideas (which surprised both the other students and us), showing that their personal learning had been enriched. The students began to devise and develop their own thoughts. They could only have acted autonomously because they regarded themselves as participants whose opinions mattered to both the other students and to us. What was interesting to note was that the students did not 
simply build on one another's thoughts in some linear, hierarchical way, but critically explored issues, and addressed the contentious issue with new ideas and information.

\begin{tabular}{|l|l|}
\hline facebook $2 \mathrm{k}$, the (3) Search for people, places and things & Q \\
\hline
\end{tabular}

Although the leamers were dogmatic, there are indications of learner autonomy. This learner demonstrated rhizomatic thinking by wondering about the future of human evolution. Although there is very little scientific basis for the learner's comments, it is interesting to note how this leamer's thinking has progressed in a rhizomatic manner.

As an educator it was not my intention in this discussion to direct or guide it along specific lines. Rather, my role in this discussion was to serve as a scientific consultant, ensuring that learning was directed towards achieving the learning outcomes.



examples of evolution in humans today, maybe you can look at those examples takings into consideration your point of view. October 29 at 6:52pm - Like

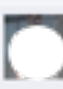

- What if humans are the final stage of evolution? Technology undergoes changes constantly - they are evolving.... http://www.solentificamerican,com/artide, cfim?id = the future-of-man October 29 at 6:54pm - Unlike ' $\$ 1$ I can see that Humans are constantly adapting to emvironment and change (dimate, etc). But that doesn't show or prove that ALL Ife originated from a single organism. October 29 at 7:07pm - Unlike ' $B 1$ Canat article that you posted a linked to indicates that we are indeed showing evolutionary changes, that would therefore contradict your post. October 29 at 7:07pm + Like

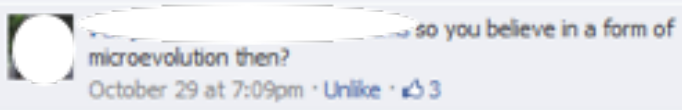

\section{This learner}

demonstrated rhizomatic thinking by first reading the comments of peers, researching the Internet autonomously and then posting a comment that was different to the initial chain of thought in the discussion.

\section{.} selection which in tern mirst of al evolutoon is based on natural your arguement invalid. If we needed to fly due to us being prey to another species our bodies would have adapted to fly, but istead our minds have evolved in order for us to create man made, either weapons (for defensive purposes) or cars, busses, planes for our own comienience. October 29 at $7: 19 \mathrm{pm}$ - Like - Natural selection is the gradual, non-random process by which biological traits become either more or less common in a population as a function of differential reproduction of their bearers. It is a key mechanism of evolution. The term "hatural selection" was popularized by Charles Darwin who intended it to be compared with
Although not aif the learners participated in every single wall post discussion, Facebook at least shows that they viewed the comments posted.

By consulting me, the learners were encouraged to do further research in order to address the questions that their peers posed in the discussion.

Figure 2: A sample of a screenshot analysis (Facebook screenshots: Grade 10 Life Sciences class) 


\section{RESEARCH STUDY 2: GRADE 11 ECONOMICS CLASS}

\section{Critical discourse analysis (CDA) of Facebook screenshots}

In this section, we look at the meaningful encounters between the students on the social media site Facebook after they had viewed two films, 'An Inconvenient Truth' and 'Into the Wild'. Using Fairclough's (2003) dialectical relational approach to the Facebook screenshots afforded us the opportunity to describe, interpret and explain the texts that arose from the online engagements between the Grade 11 Economics students in relation to the two films, which were shown to them during class.

The texts on the Facebook screenshots seem to show that many of the students argued for a socially just society, and the two films possibly played an important part in conscientising them to the various discourses arising from our own observations of the two films. From a reader's perspective, some of the Facebook comments (student UI in particular) could be considered presumptuous and naïve, while others were more informed and justifiable, though not always elaborative in the early parts of the online discussion. It could be claimed that learner UI's comment were overzealous, and this could be attributed to him improving on his previous comment to a question posed on Facebook, on the impact of sustainable development on a socially just society, perhaps to impress his peers with his newly found knowledge. We refer to him being overzealous as the text, which is essentially a verbatim copy of the Brundtland report copied from the Internet, could in some way be viewed as him taking the initiative to actively search for concepts related to sustainable development. We argue that perhaps he could be considered autonomous because he tried to provide his peers with some other information and justifiable reasons for his previous comment.

In the Facebook screenshots, it seems that many of the learners' activities point to the attainment of social justice through equity and sustainable development, using a narrative approach that is informative to both the students and the (higher) educationists. This points to an understanding of an (un)just society, perhaps through their personal experiences in society, as well as discovery from viewing the film, which can be considered heuristic.

The rhetoric of equity in society evident from these screenshots seems to point out that issues of economic and cultural (in)equality, which resonate with the apartheid frame of thinking, could be eradicated if there was unity amongst the community in addressing unequal patterns in (higher) education and in the economy. Hence, the students' arguments for a just society in the Facebook screenshots could be seen as plausible. However, not all 
students agreed with the notion of equity in society, as is evident in learner CP's comment on equity as a 'myth'. This could be attributed to the students' personal experiences in society in relation to the fallacies of the state's economic system and redress programmes. Based on the Facebook screenshots, the students were able to link the discourses of (in)equity and (un)sustainable development to issues of prejudice, discrimination and racism, without us as (higher) educationists dictating the learning experiences and forms of engagement.

Also, it can be claimed in relation to the Facebook screenshots that some of the students disagreed with the notion of sustainable development and equity in society, which can be considered critical and, in some form, also emancipatory. It is emancipatory in the light of students having the autonomy and freedom to voice their opinions without any form of restriction by the other students in the Facebook group. What is important to note from both screenshots is that the context that these students found themselves in produced the relevant texts, as stated by Fairclough. From our own observations, this could be attributed to the students' own encounters amongst one another on the Facebook group, the films that they viewed, and perhaps doing more research on the two films using the Internet.

The solutions provided by these Grade 11 students to some extent demonstrated their abilities to reflect critically on what society ought to be doing to address the aforementioned issues. The students' comments were both empathetic and encouraging, whether in relation to the environment or the redistribution of wealth to the poor, as learner SVDS states pertinently. Hence, the text that were produced can be associated with the context in which the students found themselves, that is, living in historically disadvantaged, poor areas where issues of (in)equity have hampered many communities from achieving a healthy standard of living, largely due to poor wealth redistribution policies and (un)sustainable development (as is evident from the lack of sustainable jobs in the communities).

From the Facebook screenshots it can be inferred that using the Facebook group as a means to elicit debates and discussions afforded the students opportunities to question or critique, in a deliberative manner, the questions we posed on Facebook, as well as one another's comments, justifying their points of view and actively searching for more information using the Internet in an autonomous manner. It can also be claimed from doing a CDA of the Facebook screenshots that the adoption of digital technology in this case created the conditions for students to think critically, engage deliberatively and act autonomously.

In the next section, we discuss the use of digital technology and its implications for (higher) education. 
AA

Similarty the survival of society needs a supportive natural emvironment, not one ravaged by climate change. But neither will happen unless we manage scarce resources at our disposal more successfully in both financial and environmental terms. And in terms of social impact. People are greedy.

\section{Zayd Waghid}

Does it educate people about sustaining the environment?

\section{-LG $1,2,3$ and 4}

A learner places
emphasis on
sustainability of society
through care and
management of the
environment.

U1

Sustainable development reters to a mode of human development in which resource use aims to meet human needs while ensuring the sustainability of natural systems and the environment, so that these needs can be met not only in the present, but also for generations to come. The term 'sustainable development' was used by the Brundtland Commission, which coined what has become the most often-quoted definition of sustainable development: "development that meets the needs of the present without compromising the ability of future generations to meet their own needs

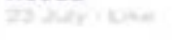

\section{"LG 3 and 4}

\section{Zayd Waghid}

So you are sayling educating people about sustainable development is a bad thing

$$
\text { T }
$$

\section{Zayd Waghid s}

00 Augurst

What impact has equality on a socially just society?

$$
\text { olv Like } \quad \text { e Commont } \rightarrow \text { Share }
$$

Be the first person to like this.

Seen by 30 people.

\section{$\mathbf{R L}$}

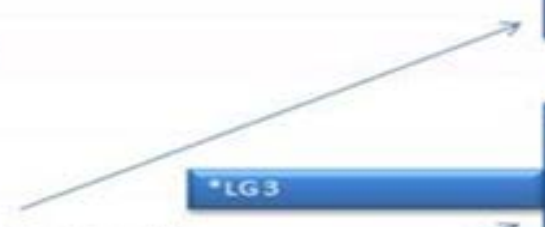

Doesn't a socially just society mean that society is equarm?

\section{AA}

Equality is important in any society because it teaches us how to five substantial

lives. They all live different lives even though they get the same. (Andrea and Sihaam)

\section{RL.}

Where did you copy that from? (suleiman)

CP
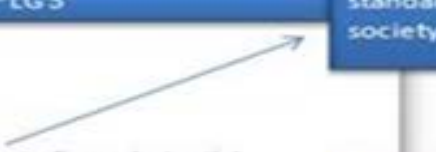

Myrole as factititator

posting a question in

order to encourage a

meaningful response

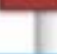

\section{A learner offering a more in}

depth clarification of

sustainable development as

evidence of enhanced

understanding of the concept

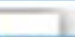

The learner is aware of

the requirements of a

just society-i.e.

equality

\section{The learner ploces}

emphasis on the

standard of tiving of

society

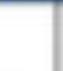

Here the learnerazain

entrases in deliberation

in trying to provide his

reasons for his

judgement

Dut if the society is socially just the equality is oready in phase

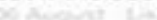

\section{SVDS}

Equality also teaches one to share resources equally amongst the rich and poor for example.

\section{-LGS}

The learner's gesture
sugsest him as
reassuring of the
positive impact equality
has on people willing to
share their resources

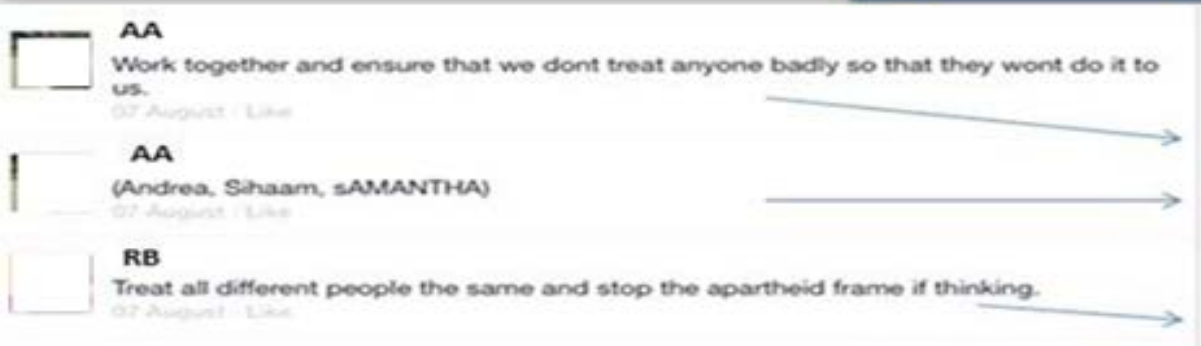

บI

let people be, they will come right eventually.

c poopla ber

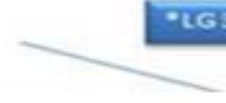

CP

but a socially just society is just a myth

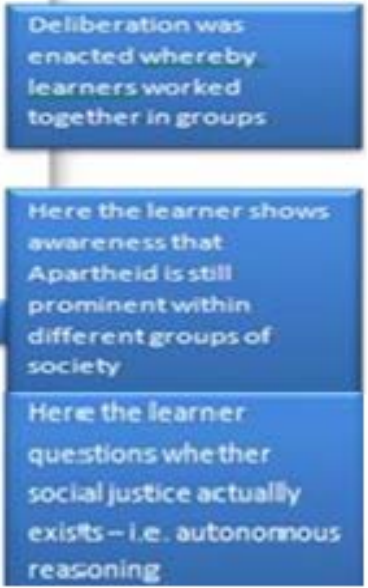




\section{Discussion}

The application of digital technology has its roots in critical theory, with Koetting (1983a) positing that digital technology in (higher) education has its theoretical base within the framework of a scientific behaviourally based model of rationality, which is partly examined by Habermas’s three forms of science: the empirical - analytic, the historical - hermeneutic, and the critical, each of which has a primary interest in technical control, mutual understanding in life, and emancipation (Nichols and Allen-Brown 2004, 12). Koetting (1983b) suggests that the application of digital technology in (higher) education in the light of Habermas's three forms of science can be shifted towards critical sciences, which would put digital technologists in the mainstream of (higher) educational thought.

In the light of Habermas's principle of emancipation through critical insight, we are of the view that, instead of conforming to some traditional teaching methodology such as the traditional 'chalk and talk' style - which in our view is usually based on some predetermined outcome and could be considered as reductionist and posing severe limits on knowledge formation - we instead adopt a teaching methodology that encourages students to experience and investigate for themselves some political or cultural issue using the Internet. This would also afford us, as critical (higher) educationists, an opportunity to examine our own educational outcomes within our practices, and hence a means of enhancing the way we use digital technologies to enhance learning through making good judgements, fostering deliberation and constructing collective meaning making.

Boyd (1991) postulates that, in today's context, students are immersed in schooling that could be considered bureaucratic, domineering and mundane, and although he views the application of digital technology in (higher) education as directed towards romance, precision and to some extent generalisation, it should invariably be aimed at the Habermasian principle of emancipation. Apple (1986) posits that the use of digital technologies should be aimed at political, economic and educational reasons. We agree with the sentiments of Apple (1986) and Boyd (1991) in that integrating digital technology in (higher) education through an emancipatory approach would be beneficial to both the students and (higher) educationists.

A lecturer at a (higher) education institution could perhaps use the Internet to introduce her economics lesson by showcasing what is currently happening in the news on a local news website, or use social media to engage with her students on issues currently affecting South Africa, such as the matter of tertiary fees protests in 2015 and the problems it poses for the economy. This will create conditions for possible deliberation and critical thinking on these political, economic and cultural issues. It could be claimed that using Facebook (as shown in 
the two cases in this article) to encourage discussions or debates on the influx of migrants from the Middle East into Europe would be an excellent setting for students to critically engage with one another, and to discover for themselves further reading on these issues using the internet.

Knowledge is only relevant when it begins with experiences and is only transformative when students begin to use their knowledge for self-empowerment and for the benefit of society - sentiments echoed by McLaren (1994). Hence, if students were more informed of the current state of affairs in the South African economy, then they would be more empowered to engage with one another, which could create more meaningful experiences in a (higher) education context. Although many critical theorists argue against the use of digital technology in (higher) education, we are of the view that, by not using digital technology at all in (higher) education, we are conforming to stagnant ways of thinking instead of innovative and dynamic ways of encouraging students to deliberate, think critically or act autonomously. Hence, as (higher) educationists we should be more open to incorporating digital technologies in (higher) education, as suggested by Altrichter et al. 1998).

Many would argue that technology could further marginalise some students and prevent them from actively engaging with others because they do not have access to the Internet, and that as (higher) educationists we should not be serving as instructors - a problem that can quickly arise if we are not aware of our own goals. We acknowledge the sentiments of those concerned, and agree that as (higher) educationists we cannot serve as instructors by just merely 'banking information' (Freire 1993), expecting of students to accept information as mere subordinates without critically questioning or challenging the status quo. To serve merely as an instructor would further marginalise students and hence we acknowledge that the application of digital technology has its limits in (higher) education. Nonetheless, to adopt a mind-set not to use technology in today's society is a bit naïve, considering that most of the world in which we live operates using some form of technology. Depending on her technological capabilities, a PhD student residing in Cape Town is able to communicate with her supervisor in Dubai using social media. Hence the issue is not whether digital technologies marginalise students, but rather whether students and (higher) educationists are in fact capable of using these technologies.

Consequently, the onus is on both tertiary institutions and the state to enhance (higher) education by cultivating students' capacities to use the Internet and to enhance their digital literacy. Amartya Sen, Nobel prize winner and economist-philosopher, uses the concept of 'human rights as capabilities', which refers to 'the substantive freedom of people to lead lives 
they have reason to value and to enhance the real choices they have' (Sen, in Vally and Zafar 2007, 67). It therefore is possible to adopt this concept in relation to (higher) education through the application of digital technology. This means that, if students are afforded equal opportunities to actively engage with one another though online group discussions (as we have shown in this article), pertaining, for example, to economic issues affecting society such as the influence of globalisation on poor economies or scientific issues such as the influence of cloning on society, then they are afforded the opportunity to make their own autonomous choices and decisions as future democratic leaders of society, premised on the principles of critical thinking and deliberative enquiry - provided they have the capabilities to achieve the aforementioned.

We argue that, as academics in (higher) education, it is our responsibility to contribute to the cultivation of autonomous learning, critical thinking and deliberation by developing, scrutinising and implementing a (higher) education curriculum through the use of digital technology, based on values, education and democracy, in order to prepare students for the social, economic and political challenges of society, and to better their lives as digitally literate critical thinkers, and democratic and deliberative citizens. As (higher) educationists we therefore would need to enact the Habermasian principle of emancipation and nurture the capabilities stated by Sen, if we were to engage with the curriculum critically using digital technologies in a (higher) education context.

\section{CONCLUSION}

In this article we have found that the educational practices of students are in consonance with an enhancement of learner participation, collaboration and deliberation as they (students) endeavour (through digital technology application) to find justifiable explanations for and understandings of contentious issues in Grade 10 Life Sciences and Grade 11 Economics classes. We argue (as teacher educators) that using the application of digital technology in a (higher) education context can only enhance effective implementation of curriculum policy. In relation to both cases facilitated through the two research designs (AR and CDA), it is claimed that the application of digital technology can help create conditions for students to engage with each other in deliberative spheres premised on the principles of critical thinking and autonomous learning. As (higher) educationists we argue that it is often better to 'listen' than to 'tell', and in encouraging students to come to speech will only enhance autonomous learning, critical thinking and deliberative enquiry, instead of dictating to students, as subordinates, what they should say or do, as this will undermine and marginalise students 
from active engagement. The use of digital technology has great potential in enhancing teaching and learning in a (higher) education context; however, this depends on whether students and (higher) educationists in fact cultivate their capabilities to do so.

\section{REFERENCES}

Altrichter, H., A. Feldman, P. Posch and B. Somekh. 1998. Teachers investigate their work: An introduction to action research across the professions. New York: Routledge.

Apple, M. W. 1986. Teachers and texts: A political economy of class and gender relations in education. New York: Routledge \& Kegan Paul.

Badat, S. 2010. The challenges of transformation in higher education and training institutions in South Africa. Johannesburg: Development Bank of Southern Africa.

Boyd, G. M. 1991. Emancipative educational technology. In Paradigms regained: The uses of illuminative, semiotic, and post-modern criticism as modes of inquiry in educational technology, ed. D. Hlynka and J. Belland, 83-92. Englewood Cliffs, NJ: Educational Technology.

Burbules, N. 2007. Networks as spaces and places: Their importance for educational research collaboration. In Educational research: Networks and technologies, ed. N. Burbules, 43-54. New York: Routledge.

Denscombe, M. 1999. The good research guide for small scale research projects. Berkshire: Open University Press.

Eisenhart, M., E. Finkel and S. F. Marion. 1996. Creating the conditions for scientific literacy: A reexamination. American Education Research Journal 33: 261-295.

Elliot, J. 1991. Action research for educational change. Milton Keynes: Open University Press.

Fairclough, N. 2003. Analysing discourse and text: Textual analysis for social research. London: Routledge.

Fairclough, N., R. Jessop and A. Sayer. 2004. Critical realism and semiosis, In Realism discourse and deconstruction, ed. J. Joseph and J. Roberts. London: Routledge.

Freire, P. 1993. Pedagogy of the city. New York: Continuum.

Gane, N. 2005. An information age without technology. Information, Communication and Society 4(8): 471-476.

Gimbert, B. and D. Cristol. 2004). Teaching curriculum with technology: Enhancing children's technological competence during early childhood. Early Childhood Education Journal 31(3): 207-215.

Hardiker, P. 1989. The organisation and management of postgraduate research projects. Leicester: Mimeo.

Higgins, S., Z. Xiao and M. Katsipataki. 2012. The impact of digital technology on learning: A summary for the Education Endowment Foundation. Durham: Durham University.

Hopson, M. S., E. Simms and J. Knezek. 1991. Using a technology-enriched environment to improve higher-order thinking skills. Journal of Research on Technology Education 34(2): 109-120.

Janks, H. 1998. Reading woman power. Pretexts: Studies in Writing and Culture 7(2): 195-211.

Jenkins, E. 1999. School science, citizenship and the public understanding of science. International Journal of Science Education 21(7): 703-710.

Jeremy, M. 2000. Changing how and what children learn in school with computer based technologies. Computer Technology 10(2): 76-101.

Jorgensen, M. and L. Phillips. 2002. Discourse analysis as theory and method. London: Sage. 
Koetting, J. R. 1983a. Philosophical foundations of instructional technology. Paper presented at the annual meeting of the Association for Educational Communications and Technology, New Orleans, LA.

Koetting, J. R. 1983b. Jürgen Habermas's theory of knowledge and human interests and educational technology: A theoretical investigation. Unpublished manuscript.

Krejsler, J. 2004. Becoming individual in education and cyberspace. Teachers and Teaching: Theory and Practice 10(5): 489-503.

MacKnight, C. 2000. Teaching critical thinking through online discussions. Educause Quarterly 4(1): $38-41$.

McLaren, P. 1994. Life in schools: An introduction to critical pedagogy in the foundations of education. New York: Longman.

McNiff, J. and J. Whitehead. 2006. All you need to know about action research. London: SAGE.

Nichols, R. G. and V. Allen-Brown. 2004. Critical theory and educational technology. In Handbook of research on educational communications and technology, ed. D. Jonassen and M. Driscoll, 129. http://www.aect.org/edtech/ed1/pdf/09.pdf (accessed 30 November 2015).

Robinson, J. P., A. Neustadtl and M. Kestnbaum. 2002. The online diversity divide: Public opinion differences among Internet users and non-users. IT and Society: 284-332.

Selwyn, N. 2011. Education and technology. London: Continuum.

Smeyers, P. and M. Depaepe, ed. 2007. Educational research: Networks and technologies. Dordrecht: Springer Press.

Underwood, J. 2009. The impact of digital technology: A review of the evidence of the impact of digital technologies on formal education. Coventry: Becta.

Vally, S. and S. Zafar. 2007. The right to basic education: State. A Conference of the Education Policy Consortium, 66-74. Johannesburg: Centre for Education Policy Development.

Van der Merwe, A. D. 2004. Evaluating the integration of ICTs into teaching and learning activities at a South African higher education institution. Unpublished doctoral dissertation. Stellenbosch: Stellenbosch University.

Wainer, J., T. Dwyer, R. S. Dutra, A. Covic, V. B. Magalhães, L. R. Ferreira, V. A. Pimenta and K. Claudio. 2008. Too much computer and Internet use is bad for your grades, especially if you are young and poor: Results from the 2001 Brazilian SAEB. Computers and Education 51: 14171429.

Wankle, C. 2011. Teaching arts and science with new social media (Vol. 3). New York: Emerald Group Publishing Limited.

Wolff-Michael, R. and S. Lee. 2003. Science education as/for participation in the community. Rethinking Scientific Literacy 88(2): 263-291. 